\title{
Cursinho Popular Emancipa: movimento de educação popular
}

Rigler da Costa Aragão1, Pablo Souza da Silva², Arlêto Vilhena da Silva Neto², Diemison Ladislau de Alencar ${ }^{4}$

\section{Resumo}

Este texto apresenta a concepção e a experiência desenvolvida no programa de extensão universitária "Cursinho Popular Emancipa: movimento de educação popular", desenvolvido na Universidade Federal do Sul e Sudeste do Pará (Unifesspa). Com o objetivo de contribuir com o acesso ao ensino superior de estudantes oriundos de classes populares e com a prática da docência pelos acadêmicos dos cursos de licenciatura, cria-se um espaço de organização e prática social destinado à juventude secundarista e universitária. O método científico de compreensão da realidade é o materialismo dialético. Exploram-se três categorias fundamentais do método: a matéria, a consciência e a prática social. O cursinho popular está cumprindo seu papel de ser uma alternativa para a juventude. Independentemente de quantos entram na universidade, consegue-se oferecer uma formação complementar, fortalecendo a formação crítica de construção de um sujeito comprometido com as transformações sociais necessárias a sua classe social.

\section{Palavras-chave}

Educação Popular. Extensão. Cursinho Popular.

1. Mestre em Geofísica pela Universidade Federal do Pará; professor efetivo na Universidade Federal do Sul e Sudeste do Pará. E-mail: rigler@unifesspa.edu.br.

2. Graduando em Matemática na Universidade Federal do Sul e Sudeste do Pará; professor no Programa Cursinho Popular Emancipa. E-mail: pablosd.silva@gmail.com.

3. Graduando em Ciências Sociais na Universidade Federal do Sul e Sudeste do Pará; bolsista de extensão; coordenador pedagógico e professor no Programa Cursinho Popular Emancipa. E-mail: arleto.silva@gmail.com. 4. Graduando em Geografia na Universidade Federal do Sul e Sudeste do Pará; coordenador pedagógico e professor no Programa Cursinho Popular Emancipa. E-mail: ladislau17@gmail.com. 


\title{
Cursinho Popular Emancipa: popular education movement
}

Rigler da Costa Aragão*, Pablo Souza da Silva**, Arlêto Vilhena da Silva Neto***, Diemison Ladislau de Alencar***

\begin{abstract}
This paper presents the conception and experience of the extension program "Cursinho Popular Emancipa: popular education movement" developed in Federal University of South and Southeast of Pará (Unifesspa). It creates an organizational space and social practice to secondary school and university students, aiming contribute to the access to higher education for students from lower classes and the practice of teaching by students of undergraduate courses. The scientific method of understanding reality is dialectical materialism. We explore three fundamental categories of the method: matter, consciousness and social practice. The preparatory course is fulfilling its role as an alternative to youth, regardless of how many enter the university could offer a complete training, strengthening the critical formation of construction of a subject committed to social change necessary for your class.
\end{abstract}

\section{Keywords}

Extension University. Education. Popular Course.

\footnotetext{
* MSc in Geophysics, Federal University of Pará, State of Pará, Brazil; professor, Federal University of South and Southeast of Pará. E-mail: rigler@unifesspa.edu.br.

** Undergraduate in Mathematics, Federal University of South and Southeast of Pará; professor, Programa Cursinho Popular Emancipa. E-mail: pablosd.silva@gmail.com.

*** Undergraduate in Social Sciences, Federal University of South and Southeast of Pará, extension scholar, pedagogical coordinator and professor at Programa Cursinho Popular Emancipa. E-mail: arleto.silva@gmail.com. **** Undergraduate in Geography, Federal University of South and Southeast of Pará, pedagogical coordinator and professor at Programa Cursinho Popular Emancipa. E-mail: ladislau17@gmail.com.
} 


\section{Introdução}

Neste trabalho, apresentamos a concepção e a experiência vivenciada pelo programa de extensão universitária "Cursinho Popular Emancipa: movimento de educação popular", desenvolvido na Universidade Federal do Sul e Sudeste do Pará (Unifesspa), refletindo a conexão da prática do cursinho popular com a concepção de educação popular defendida por Paulo Freire, Hurtado e Gutiérrez.

Este programa tem como objetivo criar espaços de discussão e prática social destinados à juventude secundarista e universitária. Isso é estimulado a partir de necessidades diferentes, mas que se cruzam: o acesso ao ensino superior e o estimulo à docência. Assim, há a contribuição ao acesso ao ensino superior de estudantes oriundos de classes populares e à prática da docência pelos alunos dos cursos de licenciatura. Esse processo formativo, vivenciado pelos acadêmicos e estudantes do ensino médio, baseia-se na ação solidária entre jovens, estando fortemente fundamentada na concepção da educação popular de construção de sujeitos construtores de sua história.

O programa integra a Rede Nacional de Cursinhos Populares Emancipa, que se diferencia por sua proposta, pois, além de preparar os jovens para a realização de um exame de seleção, prepara-os para a vida, formando-os cidadãos, a partir da compreensão da realidade regional e nacional, contribuindo para a construção da mobilização para a luta por direitos e tornandoos protagonistas na transformação da sociedade.

O método científico aplicado e de compreensão da realidade é o materialismo dialético. Exploramos três categorias fundamentais do método: a matéria, a consciência e a prática social. Para a compreensão do movimento existente na sociedade, partimos do cotidiano (a matéria) e chegamos ao político (prática social), em um processo ocorrido de forma contínua e por saltos. Para nós, o problema cotidiano (a matéria) é o sucateamento da escola pública e a exclusão de milhões de jovens do acesso ao ensino superior. A percepção desse problema e o reconhecimento de suas causas (consciência) levam-nos a uma organização política para intervir e transformar essa realidade (prática social).

Outra categoria do método é a totalidade. Compreendemos que, no seio do todo, existem contrários e contradições, coexistem fatores diferentes e mutualmente relacionados. Buscamos as conexões entre os atores e a realidade política do campo educacional, entre formuladores das políticas públicas, organizações de financiamento internacional (FMI e Banco Mundial) e organizações dos movimentos sociais (Sindicatos de Professores e o Movimento Estudantil), estes construtores da resistência e da luta contra a precarização da escola pública. Sabemos que políticas de precarização e privatização são impostas aos países periféricos, a partir de renegociações de suas dívidas externas, e conduzidas por organizações de financiamento internacional, responsáveis pela aplicação das políticas neoliberais de mercantilização dos serviços que deveriam ser dever do Estado, pois são direitos de cidadania.

Assim, entendemos a educação popular como forma dessa resistência e articulação, não só no campo educacional, mas na organização da luta por outras pautas como na luta pela reforma agrária, moradia, saneamento básico e emprego.

\section{Educação popular}

Educação popular é um processo que engloba ensino e formação voltada para o povo. É uma concepção de educação que conta com a participação da comunidade e se apoia em sua realidade, com o objetivo de formar pessoas protagonistas para a construção de mudanças. 
Educação popular é o processo contínuo e sistemático que implica momentos de reflexão e estudo sobre a prática do grupo ou da organização; é o confronto da prática sistematizada com elementos de interpretação e informação que permitam levar tal prática consciente a novos níveis da compreensão. É a teoria a partir da prática e não a teoria "sobre" a prática. Assim, uma prática de educação popular não é o mesmo que "dar" cursos de política para a base, nem ler textos complicados, nem tirar os participantes por muito tempo de sua prática, para formálos, sem tomar a própria realidade (e a prática transformadora sobre essa realidade) como fonte de reconhecimentos, como ponto de partida e de chegada permanente, percorrendo dialeticamente o caminho entre a prática e sua compreensão sistemática, histórica, global e científica sobre esta relação "entre teoria e prática". (HURTADO, 1992, p. 44-45).

Hurtado (1992) afirma que a educação popular é um processo de formação e capacitação que acontece dentro de uma perspectiva política de classe e que toma parte da ação organizada do povo. É um processo contínuo e sistemático, que implica momentos de reflexão e estudos sobre a prática do grupo.

A educação popular tem como principal característica a aprendizagem a partir da realidade, sendo também instrumento de transformação social. Freire (1996) refere-se ao povo como oprimido que, na sua visão, é aquele que não tem chance para exercer seus direitos, sendo produto de uma relação social que decorre do modo de produção capitalista, na qual não há possibilidade para o povo mudar a direção das decisões políticas do Estado. O opressor é aquele que detém poder sobre o sistema político, o sistema escolar e os meios de produção.

Em função do exposto, entendemos educação popular como um processo de pensar e refletir o conhecimento referente à realidade, buscando o envolvimento de uma base excluída e marginalizada para a auto-organização e luta por direitos na tentativa de transformar sua realidade. Segundo Freire (1996), assim como o opressor, que, para oprimir, precisa de uma teoria da ação opressora, os oprimidos, para libertarem-se, necessitam igualmente de uma teoria de sua ação.

Hurtado e Freire preocupam-se, especialmente, em exibir, cada qual, sua teoria da conscientização, baseada na busca da formação de uma consciência crítica da vida real, superando, assim, a ingenuidade que condiciona a exploração do oprimido pelo opressor, em uma sociedade capitalista, e reconhecendo o seu papel no mundo.

Os oprimidos, nos vários momentos da sua libertação, precisam reconhecer-se como homens, na sua vocação ontológica e histórica de ser mais. A reflexão e a ação se impõem, quando não se pretende, erroneamente, dicotomizar o conteúdo da forma histórica. (FREIRE, 1996, p. 57).

Para Gutiérrez (1988) e Hurtado (1992), o educador popular tem um papel eminentemente político, devendo encarar, portanto, os problemas e tomar partido frente à realidade social, e não ficar indiferente às injustiças e aos direitos violados, pois o docente, na educação popular ou na tradicional, faz política. Como tem papel importante na sociedade, ele deve refletir sobre o sentido e a finalidade de sua função, pois a educação popular pode ajudar na organização e nas reivindicações do povo. O docente deve ser consciente dos problemas sociais, por isso ele tem que estar ciente das questões teórico-práticas citadas por Hurtado (1992, p. 53):

O que conhecer, como conhecer, para que conhecer, em favor de que e de quem conhecer - e, por seguinte, contra que e contra quem conhecer - são questões teórico-práticas e não intelectuais que nos são apresentadas pela educação enquanto ato de conhecimento. 
Compreendemos a educação popular a partir da valorização e organização do oprimido e a luta por mudanças. Sem isso, não há educação popular, mas apenas reprodução de um sistema tradicional excludente e opressor. É necessária uma organização político-pedagógica que tenha, como horizonte, a mobilização e a luta por mudança para que possa acontecer uma educação popular de verdade.

O educador popular deve ser capaz de enxergar sua prática educativa como algo essencial, sendo preciso lutar e insistir em revoluções. Portanto, o objetivo comum da educação popular é o fortalecimento das classes populares, como sujeitos de produção e comunicação de saberes próprios, visando à transformação social.

\section{Os cursinhos populares}

A educação superior brasileira é marcada pela exclusão e pelo elitismo, apresentando forte aspecto de mercantilização, seja devido ao crescimento do setor privado, que detém $75 \%$ das matrículas no ensino superior, ou ao mercado de serviços criados em torno da preparação para ingresso no ensino superior. Com o sucateamento da escola pública, que oferta o ensino básico, e o número insuficiente de vagas nas universidades públicas, criouse o mercado dos cursinhos comerciais.

Naturalizou-se que, para ingressar na universidade, além da conclusão do ensino médio formal, o aluno teria que passar por uma preparação mais intensiva, oferecida pelos cursinhos comerciais. Com isso, o econômico é o primeiro requisito para uma boa preparação para exames de seleção das universidades públicas brasileiras.

Segundo o Instituto Nacional de Estudos e Pesquisas Educacionais Anísio Teixeira (INEP), há, atualmente, mais de 8,3 milhões de estudantes no ensino médio no Brasil. Desses, 85,9\% estão matriculados em escolas públicas estaduais de todo o país e pouco mais de $11 \%$ frequentam escolas privadas. Apesar da existência de programas de inclusão social como forma de ampliar a entrada de estudantes oriundos de escolas públicas nas universidades brasileiras, por meio da inscrição gratuita no vestibular, bolsas de apoio, sistema de cotas etc., tais alunos ainda são minoria em nossas universidades.

O cursinho popular se integra à educação popular, já que, como conceituado por Hurtado (1992), ela é um processo de formação e capacitação que se dá dentro de uma perspectiva política de classe e que toma parte da ação organizada do povo. Esse processo é contínuo, sistemático e implica momentos de reflexão e estudo sobre a prática do grupo.

A educação popular tem como principal característica a aprendizagem a partir da realidade, sendo também instrumento de transformação social. É justamente com essa proposta que o movimento de cursinhos populares se ampliou, e, em muitos casos, a iniciativa partiu da própria juventude.

Segundo Mendes (2011, p. 42), a partir de 1990, a criação de cursinhos populares protagoniza uma "verdadeira proliferação, especialmente nos grandes centros urbanos". Em diversas universidades, ocorreu, no interior dos campi (na maioria das vezes articulada pelo movimento estudantil), a institucionalização desses cursinhos como projetos de extensão universitária, ao mesmo tempo em que outros projetos se estabeleceram, como a EDUCAFRO (ação do Movimento Negro) e outros vinculados a movimentos de bairro. Dentre essas várias experiências, há uma multiplicidade de participantes, arranjos institucionais, propostas pedagógicas e relações com a Universidade. A pluralidade e a informalidade, aliadas ao idealismo de alguns estudantes universitários, são algumas das características marcantes dos cursinhos populares, o que os tornam laboratórios de experiências pedagógicas que ainda carecem de um melhor entendimento 
acerca das possibilidades e limites que encerram.

\section{A Rede Emancipa}

A Rede Emancipa é uma rede de cursinhos pré-vestibulares, cuja coordenação e organização são voluntárias. Sua ação se faz a partir da construção de cursinhos populares em espaços cedidos e seu objetivo é a luta pelo direito à universidade para todos, sobretudo para alunos oriundos da escola pública.

Para Mendes (2011), a Rede Emancipa acredita na capacidade de organização coletiva para um fim comum de intervir e transformar a realidade educacional brasileira, com a intenção de tornar possível o acesso de estudantes oriundos de escola pública ao ensino superior e lutar para uma maior democratização e reformulação do ensino no país.

Em 2008, foram fundados três cursinhos: Cursinho Chico Mendes, Cursinho Paulo Freire e Cursinho Popular do Butantã, todos na cidade de São Paulo. Hoje, a Rede já conta com doze unidades só no Estado de São Paulo, chegando a outros, como Rio Grande do Sul, Pará, Rio de Janeiro e Distrito Federal, oferecendo mais de 1.500 oportunidades para quem almeja conquistar uma vaga na Universidade.

Com uma proposta que vai além do ensino para um exame de seleção, a Rede propõe ao estudante um espaço inovador de discussão da realidade regional e nacional, criação e recriação do saber acerca do mundo e da vida. A atividade da Rede Emancipa é desenvolvida em igrejas, centros comunitários, escolas públicas e universidades como programas/ projetos de extensão, não se restringindo apenas à sala de aula, pois a educação não está só ali.

O Emancipa organiza, ainda, exibições de filmes e debates e incentiva a participação dos alunosnosmovimentossociais, conformerelatado por um de seus alunos de 2013, que, atualmente, é estudante de Ciências Sociais da Unifesspa:
A interação dos professores e alunos, porque na escola tem aquela coisa do professor rígido, aquele professor sério. Já no Emancipa, não tem essa coisa, no caso, por todos serem jovens da mesma idade tem aquela interação, todo mundo é amigo, e não tem aquela relação do professor rígido, todo mundo é amigo, todo mundo tá disposto a aprender [...] antes de conhecer o Emancipa, eu não tinha consciência do que era política, formação política, nada, a minha vida no caso se restringiu ao ensino médio. O Emancipa me ensinou que, na verdade, não acaba lá, eu posso buscar conhecimento, eu posso transformar a minha vida em algo significativo, não só pra mim, mas como para outras pessoas. Então é uma coisa que não vai acabar no ENEM, não vai acabar em outras provas de vestibulares, vai ser uma formação pra vida, um aprendizado, o que a gente aprende a questão da interação entre aluno e professor, a questão de a gente lutar por nossos direitos, as questões políticas, reinvindicações, exatamente como o título sugere "emancipação" o ato de tornase emancipado, tudo isso foi muito bem discutido. (M. V., 2014).

O Emancipa, em todo Brasil, participou ativamente das manifestações que tomaram o país em 2013. Em Marabá, no Pará, o cursinho Emancipa incentivou alunos e professores a participarem dos atos ${ }^{5}$, debatendo a conjuntura política, para que eles refletissem sobre as pautas das manifestações e compreendessem suas realidades e a necessidade de organização para reivindicar.

O cursinho foge do tradicional currículo conteudista dos cursinhos pré-vestibulares, mas sem deixar de abarcar o conhecimento necessário para os vestibulandos. Entende-se que a compreensão da realidade está ligada a todas as áreas do conhecimento e que ultrapassa as fronteiras que as diferencia para fins didáticos ou metodológicos, tentando superar a forma fragmentada que é apresentada e também aproveitar o conhecimento produzido pelos movimentos sociais. Para isso, periodicamente,

5. Esses atos foram importantes para o congelamento da tarifa de transporte urbano em Marabá-PA. 
o cursinho debate problemáticas que estão no centro das atenções, como foi o caso da privatização da água e a construção da hidrelétrica de Marabá. A partir dessas temáticas, buscamos ouvir o posicionamento dos movimentos sociais que contestavam contra essas ações, como o Sindicato dos Urbanitários e o Movimento dos Atingidos por Barragens $(\mathrm{MAB})$, mostrando que os movimentos sociais produzem conhecimento e que os jovens podem se organizar e lutar juntos por direitos. Assim, como também quando convidamos o Movimento dos Trabalhadores Sem Terra (MST) para debater os conflitos agrários constantes na região.

Além disso, o Emancipa viabiliza a interação entre os professores das áreas de exatas, humanas e biológicas, por meio de aulas com temáticas interdisciplinares. Ação essa reforçada com a criação de uma equipe de professores (acadêmicos do curso de Direito) que ministram aulas sobre direitos humanos e organização do Estado, o que possibilita o conhecimento por parte dos alunos sobre esses temas e a importância deles na formação de cidadãos críticos em nossa sociedade.

Um exemplo de ação e organização da juventude foi a mobilização realizada no dia 30 de junho de 2015, data em que o Congresso votou a favor da redução da maioridade penal. Antes, foi realizado um debate sobre o tema e, posteriormente, foi proposta uma chamada a outros movimentos de juventude para realizar um ato contra a redução da maioridade penal como forma de fortalecer as manifestações que ocorreriam nacionalmente. Nessa ação, o Emancipa mostrou seu protagonismo na articulação, mobilização e diálogo com o povo, tal como se pensa a educação popular, já que foram seus professores e alunos que mobilizaram as escolas públicas da cidade a se posicionarem contra a proposta de redução da maioridade penal. Dessa forma, aliaram-se debate, ação e organização de setores excluídos.

\section{Nossa concepção de extensão universitária}

A extensão universitária tem sido compreendida, nos últimos anos, como uma forma de prestação de serviços em uma perspectiva neoliberal de mercantilização da universidade públicas brasileiras. Os serviços pagos se proliferaram com a justificativa de extensão universitária, tornandose uma alternativa de receita viável para docentes e instituições. Surgem, assim, os projetos de consultoria para o setor privado, cursos pagos e programas assistencialistas, fazendo com que a extensão universitária se desconecte da pesquisa e do ensino.

No projeto Cursinho Popular Emancipa, compreendemos a extensão como indissociável da pesquisa e do ensino, posto não existir prática sem teoria, sendo que a prática consolida a teoria. A Universidade deve ter contato com os movimentos sociais e setores organizados e não organizados da sociedade, que interagem e produzem conhecimento, mesmo que não sistematizado. Assim, não existe extensão sem pesquisa, posto ser necessário referencial teórico e metodológico para orientar a ação e sistematizar as experiências, transformandoas em referencial para outras ações. Com o cursinho, apesar de ter características assistencialistas, pois parte da ação voluntária, tem-se a clareza de que a tarefa não é reduzir o dever do Estado com a educação, mas, sim, cobrar mais ainda seu compromisso. O diferencial está em partir de uma ação assistencial para poder se ampliar a ação enquanto organização e suas relações com movimentos sociais e, principalmente, com a juventude. Boaventura Sousa Santos (2008, p. 54) expressa uma concepção de extensão universitária em conexão com a importância dos cursinhos populares nas universidades:

É preciso evitar que ela seja orientada para 
atividades rentáveis com o intuito de arrecadar recursos extra-orçamentários. Nesse caso, estaremos perante uma privatização discreta (ou não tão discreta) da universidade pública para evitar isso, as atividades de extensão devem ter como objetivo prioritário [...] o apoio solidário na resolução dos problemas da exclusão e da discriminação sociais e de tal modo que nele se dê voz aos grupos excluídos e discriminados.

O apoio solidário mencionado pelo autor é motivado pela compreensão de que a juventude é a parte da população mais afetada pelas mudanças que ocorrem no mundo do trabalho, seja em momento de crises mundiais ou mudanças estruturais na sociedade como as ocorridas nos últimos trinta anos. Em uma sociedade de consumo, a juventude é cada vez mais estimulada a entrar no mercado de trabalho, seja no mercado formal ou informal, com perspectiva de ascensão social ou pela simples sobrevivência, colocando a possibilidade de continuidade dos estudos como algo improvável, realidade comum aos estudantes da escola pública. Portanto, coloca-se a extensão universitária a serviço da organização e da luta dos jovens.

\section{O educador popular}

Os educadores, antes de tudo, precisam ter uma formação política sólida, para que, com o conhecimento da realidade dos oprimidos, possam atuar junto à sociedade, à procura de avanços dentro das demandas sociais e históricas que os oprime, buscando a libertação por meio da educação, como bem retratou Florestan Fernandes (apud OLIVEIRA, 2010, p. 130-131):

Mudança requer luta e luta social entre classes. Um professor deve aprender a pensar em termos de lutas de classes mesmo que não seja marxista. [...], porque mudança implica luta e luta social. Se o conservador quer mudar alguma coisa, quer fazê-lo para preservar suas posições de poder ou, então, para amplificá- las, para não correr riscos; o reformista que mudar para conquistar posição de poder; por sua vez, o revolucionário quer mudar porque se identifica com classes que são portadores de ideias novas a respeito da natureza, do conteúdo da civilização e da natureza do homem.

O professor precisa ter consciência da amplitude e da complexidade da realidade, principalmente, quando se trata de comunidades mais carentes, em que seu papel permitirá aos alunos um acesso a meios que podem tirá-los de uma situação de dependência. Para isso, objetiva-se ir além de uma ação utilitarista de proporcionar experiência a alunos de licenciatura dos cursos da Unifesspa. As atividades realizadas, como as rodas de conversas, têm como objetivo aproximar esses jovens e quebrar a barreira entre professores e alunos, no debate de temas que afetam todos, por estarem eles inseridos em uma mesma realidade e sofrendo com os mesmos problemas sociais, como a falta de acesso à cultura, ao esporte, ao lazer, à segurança, à saúde e à educação.

Todos os debates realizados buscaram sempre uma aproximação com outros movimentos sociais, reivindicando a concepção que compreende a educação popular como educação realizada pelos movimentos sociais. Assim, acreditando que a dinâmica do cursinho leva à auto-organização dos jovens, evoluindo para uma ação autônoma e independente, ou seja, movimento de juventude com suas pautas e bandeiras de lutas.

Na educação popular, o educador é o orientador de um processo socioeducativo capaz de construir uma consciência crítica em relação à manipulação política pelas classes dominantes. Sendo assim, o educador popular reflete a educação e sua própria prática, trabalhando o aluno como um todo, para uma educação popular eficaz, democrática e estimuladora da crítica e da reflexão por parte dos alunos. Esse 
educador respeita a individualidade, a cultura e os saberes de seus educandos.

\section{Considerações finais}

O projeto contribui com a formação docente dos alunos dos cursos de licenciatura da Unifesspa, por meio das aulas, orientações e rodas de conversas, em que foram debatidas temáticas regionais e nacionais. Sem dúvida, fortalece a iniciativa à docência, mas, vai além de formação dos acadêmicos por contribuir para a compreensão de sua realidade e para a importância da ação docente nas mudanças que devem ocorrer na sociedade.

O cursinho cumpre seu papel de ser uma alternativaparaajuventude. Independentemente de quantos entram na universidade, oferecemos uma formação completa, fortalecendo a formação crítica de construção de um sujeito comprometido com as transformações sociais necessárias para sua classe social. A experiência de um ano inteiro ficará para vida e o conhecimento adquirido contribuirá no futuro para melhoria da condição de vida desses alunos.

Em 2015, iniciamos o quarto ano de realização do programa que vem acumulando boas experiências e, consequentemente, aprofundando as contradições. O Cursinho Popular Emancipa vive um processo de expansão que vai desde a quantidade de professores voluntários até a quantidade de alunos atendidos por ano. Já participaram 300 alunos e 30 professores. Isso estimula a contradição entre crescer e manter-se a politização e a perspectiva de organização de um movimento de juventude de luta pelo direito ao ensino superior (nosso objetivo) versus se limitar a uma ação assistencialista de utilização de um trabalho docente precarizado, que tenta amenizar a ausência do Estado. Para enfrentarmos essas contradições, é necessária a aproximação com os movimentos sociais que enfrentam a desvalorização da educação pública, como Movimento Estudantile Sindicatos de Professores, no exercício da solidariedade a outros movimentos em luta por direitos.

O Emancipa na Unifesspa já é considerado um projeto vitorioso que se consolida. A cada ano, tem contribuído para que jovens de classes populares ingressem no ensino superior. Seu reconhecimentonãovemapenaspelaquantidade de aprovações nos processos seletivos, mas pela ocupação do espaço universitário por jovens que veem a educação e a universidade pública como meio de mudança de sua condição social.

\section{Referências}

FREIRE, P. Pedagogia do oprimido. Rio de Janeiro: Paz e Terra, 1996. 1997.

Pedagogia da autonomia: saberes necessários à prática educativa. São Paulo: Paz e Terra,

GUTIÉRREZ, F. Educação como práxis política. São Paulo: Summus, 1988.

HURTADO, C. N. Educar para transformar, transformar para educar: comunicação e educação popular. Petrópolis: Vozes, 1992.

MENDES, M. T. Inclusão ou emancipação: um estudo do Cursinho Popular Chico Mendes/ Rede Emancipa. 2011. 137 f. Dissertação (Mestrado em Educação) - Faculdade de Educação, Universidade Federal do Rio Grande do Sul, Porto Alegre, 2011. Disponível em: <http://www. lume.ufrgs.br/bitstream/handle/10183/33673/000789415.pdf?sequence=1>. Acesso em: 17 dez. 2014. 
OLIVEIRA, M. M. de. Florestan Fernandes. Recife: Fundação Joaquim Nabuco; Massangana, 2010. SANTOS, B. S. de. A Universidade no século XXI: para uma reforma democrática e emancipatória da Universidade. Disponível em: <http://www.ces.uc.pt/bss/documentos/auniversidadedosecXXI. pdf $>$. Acesso em: 17 dez. 2014.

Submetido em 23 de março de 2015.

Aprovado em 6 de julho de 2015. 